\title{
Investigate the Relationship between Spiritual Intelligence and Emotional Intelligence with Resilience in Undergraduate (BA) Students
}

\author{
Fatemeh Nemati Sogolitappeh ${ }^{1}$, Amjad Hedayat ${ }^{2}$, Mehrdad Rezaee Arjmand ${ }^{3}$, \\ Mohamad Khaledian ${ }^{4,}$ \\ 1Department of Psychology, University of Tabriz, Tabriz, Iran \\ ${ }^{2}$ Department of Social Science, Payame Noor University, PO BOX 19395 - 3697, Tehran, Iran \\ ${ }^{3}$ Department of Media Management, Payame Noor University, Tehran, Iran \\ ${ }^{4}$ Department of Psychology, Payame Noor University, PO BOX 19395 - 3697, Tehran, Iran \\ Mohamad_khaledian22@yahoo.com
}

Keyword: emotional intelligence, spiritual intelligence, resilience

\begin{abstract}
The purpose of the present study is to investigate the relationship between spiritual intelligence and emotional intelligence with resilience in undergraduate (BA) students. The population of the study included all students of Payame Noor University in Ghorveh city during 2016-2017 academic years. According to the principles of statistical methodology for correlational studies, 100 students from different disciplines were selected as sample of the study using simple random sampling method. In this research, King's Spiritual Intelligence Questionnaire, Bar-Ann 90questions Emotional Intelligence Questionnaire, and Conner and Davison resilience questionnaire were used. Descriptive statistics (mean and standard deviation) and inferential statistics (Pearson correlation coefficient and multiple regressions) were used to analyse the data. The results of this study showed that there is a significant positive correlation between spiritual intelligence and emotional intelligence and resilience, and also there is a significant positive correlation between emotional intelligence and resilience. Regression coefficients showed that spiritual intelligence and emotional intelligence predict $53.9 \%$ of the variation in resiliency.
\end{abstract}

\section{Introduction}

The Beginning of student period is one of the most important stages of life; because, during this period one can prepare oneself for future life after graduation. If the a person intention is merely graduation from university, get his certification, and find a job consistent with his field of study, The possibility of a significant impact on the live of the individual will be weak. Scientific findings show that mental health is one of the most important needs of today's human being and accommodating it requires the person to know himself exactly, understand others, establish effective communication with them, Identify and control the negative emotions and daily stresses, solve effectively his problems, and adopt opt decision. He should not also think cliché and should not accept the input information without critical thinking [1]. There is an aspect of intelligence, called spiritual intelligence that is completely unique and humanistic. In distinguishing between spirituality and spiritual intelligence, it should be noted that spirituality is more an experiential concept; while spiritual intelligence consists of three integral parts: sensory, conceptual, and emotional. Spirituality also refers to searching, experiencing, divinity, searching ultimate meaning, higher awareness, and supernatural dimension; while spiritual intelligence refers to the prediction of performance and compatibility to capabilities obtained from these issues [2]. Zohar and Marshall presented spiritual intelligence as a combination of psychological, philosophical and religious concepts in 2000 [3]. In their view, spiritual intelligence is an intelligence that can broaden and enrich our status and activities; an intelligence that determines an activity or a way of life to be more meaningful than other activities or ways of life. Spiritual intelligence is achieved by a combination of spiritual abilities and interests, personality traits, cognitive abilities and neurological processes [4]. 
The most important applications of spiritual intelligence are: 1. generating composure and relaxation, in a way that affects the effectiveness of the individual; Establishing mutual understanding and consensus between individuals; and 3. managing changes and removing obstacles. Self-awareness is the key merit of spiritual intelligence. The growth of spiritual intelligence means deeper awareness of oneself as an immaterial being; in fact, it is the source of non-objective talents that have not been discovered previously. When one's consciousness is raised and used, one's perception creates a sense of security, and thus his performance improves in the workplace [5].

Emotional intelligence is a subject that tries to explain and interpret the status of human emotions, feelings and abilities [6]. Emotional intelligence has been defined as the ability to understand the emotions in order to evaluate one's thoughts and moods and regulate them in a way that promotes rational and emotional development [7]. The concept of emotional intelligence provides a new depth to human intelligence. This is intelligence of tactical ability (individual performance), whereas cognitive intelligence is a strategic capability (long-term capability). Emotional intelligence can predict success because it shows how a person uses knowledge in reallife success. Emotional intelligence is a type of social intelligence that is a good predictor of efficiency in specific areas such as occupational and educational performance. In other words, emotional intelligence is the ability to control the emotions of one and others [8-9]. Emotional intelligence increases awareness of feeling and its use for proper decision making in life, it also increases the ability to tolerate mental trauma and to control psychological disturbances; finally it also enhances self-esteem and internal control of individuals [10]. Emotional intelligence refers to the ability to understand the environment properly, to have self-motivation, and to recognize and control one's and other's feelings (so that this process can facilitate thinking and communication) [11]. In other words, emotional intelligence is the ability to control one's feelings and emotional tendencies, to understand the most private feelings of others, to be quiet and wellbehaved in human relationships with others, as well as to have self-control, passion, enthusiasm and perseverance [12]. Emotional intelligence involves recognizing and controlling one's emotions. In other words, a person with high emotional intelligence combines three components of emotion successfully: cognitive component, physiological component, and behavioural component. Management science texts believe that leaders and managers with higher emotional intelligence have more control over their organization and can manage it more efficiently. New findings suggest that employees with high conscientiousness and high sense of responsibility, but lacking emotional and social intelligence, have a weaker performance compared to similar employees with high emotional intelligence.

Resilience is also a positive adaptation in response to adverse situations. In fact, resilience is not merely a passive resistance to injuries or threatening conditions. Rather, the resilient person is an active participator and contributor to his surrounding environment [13]. Psychological capital is composed of positive psychological variables that can be measured and developed; they can also be managed [14]. Resilience is a factor that helps individuals to confront and adapt to difficult and stressful situations [15]. Resilience increases the ability to adapt to pain [16]. Resilience also prevents psychological problems in young people and protects them against the psychological effects of troublesome events [17]. Resilience is a feature that occurs naturally. It refers to a dynamic process that human beings display as a positive adaptive behavior when faced with adverse conditions or emotional trauma. Resilience is also a positive response to adverse situations In fact; resilience is not merely a passive resistance to injuries or threatening conditions. Rather, the resilient person is an active participator and contributor to his surrounding environment [13]. Resilience is one of the normal concepts and components of positive psychological study and refers to the dynamic process of positive conformation with bitter and unpleasant experiences [18], and is beyond survival from stresses and tensions of life.

Garmezy and Masten defined resilience as a process of ability or as the consequence of successful adaptation, despite threatening conditions. Indeed, resilience is a phenomenon that results from the natural adaptive responses of human beings and despite one's confrontation with 
serious threats, enables the person to succeed and overcome threats [19]. Rutter considers resiliency as the interaction between risk factors and protective factors [20]. Risk factors refers to any condition or event that results in incompatible consequences, but low socio-economic conditions, extensive social harm, or parental divorces are commonly known as risk factors. Protective factors also apply to any event or condition that protects a person from harm, but personality traits, family factors, and social protection are commonly known as protective factors [21]. The results of Keshavarzi and Yousefi research on the relationship between emotional intelligence, spiritual intelligence and resilience showed that there is a correlation between spiritual intelligence and spiritual intelligence, and spiritual intelligence predicts the total score of resilience positively and significantly[2]. The results of Hajian et al. research on the relationship between spiritual intelligence and emotional intelligence showed that there is a positive and significant relationship between spiritual intelligence and emotional intelligence [22]. The results of Haddadnia and Jokar's research on the relationship between spiritual intelligence and emotional intelligence with organizational citizenship behaviours (OCB) showed that there is a positive and significant relationship between spiritual intelligence and emotional intelligence and citizenship behavior [5]. The results of Baezzat and Sharifzadeh study on the relationship between spiritual intelligence and emotional intelligence with job stress in university staff showed that there is a negative, significant relationship between spiritual intelligence components such as goodness, truth and honesty with job stress [23].

As students begin their studies at universities, they face up new events and challenges that they may not have experienced in advance, achieving success in such new conditions requires adaptability and healthy conformity. These important requirements can be achieved through the promotion of spiritual intelligence, emotional intelligence and Resilience, subsequently this achievement lead to successful academic performance and satisfaction with life. Possessing spiritual intelligence, emotional intelligence and resiliency enables individuals to cope with stressful situations, control their tension in the face of stress, have a high ability to solve and deal with problems, have realistic perspective about themselves, to be less affected by daily events, and to be optimistic and hopeful; therefore, in pursuit of social, cultural and economic development through the enrichment of mental capacity, investing on students as human resources is inevitable. It is hoped that based on the findings and results of this study, we can offer ways to recognize the factors affecting the spiritual intelligence, emotional intelligence and resiliency as well as its barriers, so that we can organize students' behavior in a consistent way and provide the ground for reducing the problems of higher education system in Ghorveh city and contribute the students to a healthy and developed life, so, the aim of the present study is to investigate the relationship between spiritual intelligence, emotional intelligence and resilience in undergraduate (BA) students. The following assumptions are presented:

1. There is a relationship between spiritual intelligence, emotional intelligence and student resilience.

2. There is a relationship between spiritual intelligence and student emotional intelligence.

3. There is a relationship between spiritual intelligence and student resilience.

4. The components of spiritual intelligence predict resilience.

5. The components of emotional intelligence predict resilience.

\section{Methodology}

The method of the research is of correlational type. The population of the study included all students of Payame Noor University in Ghorveh in 2016-17 academic years. According to the principles of statistical methodology for correlational studies, 100 students from different disciplines were selected as sample of the study using simple random sampling method. In this research, King's Spiritual Intelligence Questionnaire, Bar-Ann 90-questions Emotional Intelligence Questionnaire, and Conner and Davison resilience questionnaire were used. Descriptive statistics (mean and standard deviation) and inferential statistics (Pearson correlation coefficient and multiple regressions) using SPSS_20 software were used to analyse the data. 


\section{Research Instruments}

King's Spiritual Intelligence Questionnaire is an autoregressive scale, the main form of which consists of 83 articles. In this study, the 24-item short form was used [24]. The 24-item short form was used in this study. This scale consists of four dimensions: Conscious State Expansion, Critical Existential Thinking, Transcendental Awareness, and Personal Meaning Production. A five scale scoring - from I totally agree (5) to I totally disagree (1) - was given to each article. The total score of the scale is obtained from the sum of obtained scores of articles. Hossein Chari and Zakeri [25], Keshavarzi and Yousefi [2], has affirmed the reliability and validity of the scale.

Bar-on emotional intelligence questionnaire was designed for the first time in 1980 that contains 133 questions that is thought to be the first valid cross cultural questionnaire to measure the emotional intelligence. This questionnaire was revised in 1997 and the number of its questions was reduced to 117 . This revision administered on 3831 people from six different countries was standardized in north America .Answers were analysed through the factorial analysis and in the end a general scale for EQ , 5 mixed scales and 15 subscales were explained. In Iran, this test was administered on the university of Tehran students in 2006 by Dehshiri whose questions had been reduced to 90 questions. In this research, Dehshiri has applied the retest method and the Cronbach alpha to estimate the reliability [26]. The answers of the questionnaire have been adjusted on the 5 degree scale in the Lickert scale (Totally agree, agree, somewhat, disagree, totally disagree) [27]. To estimate the reliability, two methods were used. The retest reliability or the temporal consistency coefficient was reported 0.85 after one month and 0.75 after four months. The reliability level of the test in single couple method was $0.88 \%$ and based on the Cronbach alpha it was 0.93 [28].

Conner-Davidson Resilience Scale (CD-RISC): The Connor and Davidson Resiliency Scale includes 25 five-choice items (totally incorrect, rarely correct, sometimes correct, often correct and always correct) which have been adapted by Mohamadi for use in Iran. The minimum score for this Test is 0 and the maximum is 100. The scale's validity (by way of factors analysis and convergent and divergent validity) and reliability (by way of retest and Cronbach's alpha) were established by the test's developers in different groups (normal and in danger). In Amini's research the Cronbach's alpha of 0.83 was obtained for the reliability of this Test. Grading spectrum of five choice questions includes 0 for totally incorrect, 1 for rarely correct, 2 for sometimes correct 3 for often correct and 4 for always correct. People scoring over 60 will be considered as resilient people [29].

\section{Results}

The purpose of the present research is to analyse relationship between spiritual Intelligence, emotional Intelligence and Resiliency in visiting lecturers. Descriptive data of scores of spiritual Intelligence, emotional Intelligence and Resiliency, Pearson correlation coefficient and regression are given in the following Table.

Table 1. Mean and standard deviation of spiritual Intelligence, emotional Intelligence and Resiliency.

\begin{tabular}{|c|c|c|}
\hline Variables & Mean & Standard deviation \\
\hline spiritual Intelligence & 60.3 & 5.65 \\
\hline emotional Intelligence & 319.82 & 9.01 \\
\hline Resiliency & 60.19 & 5.83 \\
\hline
\end{tabular}

Table 1 shows descriptive data related to mean and standard deviation of two variables of spiritual Intelligence, emotional Intelligence and Resiliency. 
Table 2. Kolmogorov-Smirnov test (KS test) to analyse normality of scores in spiritual Intelligence, emotional Intelligence and Resiliency.

\begin{tabular}{|c|c|c|c|c|}
\hline Factor & $\begin{array}{c}\text { Level of } \\
\text { significance }\end{array}$ & Error amount & $\begin{array}{c}\text { Hypothesis } \\
\text { confirmation }\end{array}$ & Conclusion \\
\hline spiritual Intelligence & 0.263 & 0.05 & $\mathrm{H} 0$ & Normal \\
\hline emotional Intelligence & 0.052 & 0.05 & $\mathrm{H} 0$ & Normal \\
\hline Resiliency & 0.422 & 0.05 & $\mathrm{H} 0$ & Normal \\
\hline
\end{tabular}

Given the results in Table 2 and since significance level for all components is greater than 0.05 , so these variables have normal distribution. To test hypotheses, parametric tests are used.

Table 3. Result of Pearson correlation coefficient test between spiritual Intelligence and emotional Intelligence with Resiliency.

\begin{tabular}{|c|c|c|c|}
\hline Pearson correlation & 1 & 2 & 3 \\
\hline spiritual Intelligence & 1 & 0.703 & 0.54 \\
\hline emotional Intelligence & 0.703 & 1 & 0.374 \\
\hline Resiliency & 0.54 & 0.374 & 1 \\
\hline $\mathrm{N}=100$
\end{tabular}

Given Table 3, since significance level is less than 0.05 , consequently, $\mathrm{H} 0$ is rejected and $\mathrm{H} 1$, that is, research hypothesis -positive relationship between spiritual Intelligence and emotional Intelligence - is confirmed. As observed at $95 \%$ level, there is positive and significant relationship between spiritual Intelligence and emotional Intelligence and its correlation coefficient equals 0.703. Given Table 3, since significance level is less than 0.05 , consequently, $\mathrm{H} 0$ is rejected and $\mathrm{H} 1$, that is, research hypothesis - positive relationship between spiritual Intelligence and Resiliencyis confirmed. As observed at $95 \%$ level, there is positive and significant relationship between spiritual Intelligence and resiliency and its correlation coefficient equals 0.54. Also given Table 3, since significance level is less than 0.05 , consequently, $\mathrm{H} 0$ is rejected and $\mathrm{H} 1$, that is, research hypothesis -positive relationship between emotional Intelligence and Resiliency- is confirmed. As observed at $95 \%$ level, there is positive and significant relationship between emotional Intelligence and resiliency and its correlation coefficient equals 0.374 .

Table 4. Correlation between variables (regression adequacy index).

\begin{tabular}{|c|c|c|c|c|}
\hline Model & $\begin{array}{l}\text { Correlation } \\
\text { coefficient }\end{array}$ & $\begin{array}{l}\text { Coefficient of } \\
\text { determination }\end{array}$ & $\begin{array}{l}\text { Moderated coefficient } \\
\text { of determination }\end{array}$ & $\begin{array}{l}\text { Error standard } \\
\text { deviation }\end{array}$ \\
\hline 1 & 0.539 & 0.29 & 0.275 & 4.96 \\
\hline
\end{tabular}

Table 4 shows that correlation between independent variable and dependent variable equal 0.54 . Coefficient determination is 0.29 and this value shows that $53.9 \%$ changes of resiliency are related to Spiritual Intelligence and emotional Intelligence. In other words, Spiritual Intelligence and emotional Intelligence predicts $53.9 \%$ of resiliency changes.

Table 5. F test (variance analysis) for significance of regression.

\begin{tabular}{|l|l|l|l|l|l|l|}
\hline Model & Changes & Squares sum & df & Squares mean & Statistic & Sig \\
\hline \multirow{4}{*}{1} & regression & 975.75 & 2 & 487.87 & 19.82 & 0.001 \\
\cline { 2 - 7 } & residual & 2387.64 & 97 & 24.61 & & \\
\cline { 2 - 7 } & total & 3363.39 & 99 & & & \\
\hline
\end{tabular}

Given Table 5 the calculated significance level for this statistic equals 0.001 and this shows significance of regression at $95 \%$. Regression models confirm normality assumption of the data. Therefore, the estimated linear regression model is acceptable. 
Table 6. Significance of regression coefficients for spiritual Intelligence, emotional Intelligence and Resiliency.

\begin{tabular}{|c|c|c|c|c|c|c|}
\hline \multicolumn{2}{|c|}{ Model } & \multicolumn{2}{|c|}{ Non-Standard coefficient } & $\begin{array}{c}\text { Standard } \\
\text { coefficient }\end{array}$ & \multirow{2}{*}{ Sig. } & \\
\cline { 3 - 6 } \multicolumn{2}{|c|}{1} & B & Std. Error & Beta & & \\
\hline & Constant & 28.25 & 20.38 & & 1.39 & 0.169 \\
\cline { 2 - 6 } & $\begin{array}{c}\text { spiritual } \\
\text { Intelligence }\end{array}$ & 0.564 & 0.124 & 0.545 & 4.537 & 0.000 \\
\hline & $\begin{array}{c}\text { emotional } \\
\text { Intelligence }\end{array}$ & -0.006 & 0.078 & -0.010 & -0.082 & 0.935 \\
\hline
\end{tabular}

The inserted variable in regression equation is the main core of regression analysis given in Table 6.

\section{Discussion}

The purpose of this study was to investigate the relationship between spiritual intelligence and emotional intelligence with resilience in university students. According to the findings of this study, it can be concluded that there is a significant positive relationship between spiritual intelligence and emotional intelligence with resilience, which is in line with the results of similar studies, Such as Keshavarzi and Yousefi [2], Baezzat and Sharifzadeh [23], Hajian et al. [22], and Haddadnia and Jokar [5]. To explain these findings it can be said that people with high spiritual intelligence can adopt diverse methods to manage others and establish communication and interaction with them. The main features of spiritual intelligence are individual confidence, effectiveness, establishing communication, interpersonal understanding, managing change and moving from difficult paths, which can enhance resilience and reduce stress. Research shows that spiritual intelligence can be used in many areas of work. According to George, the most important applications of spiritual intelligence in the workplace are creating peace of mind and mutual understanding among colleagues, which in turn result in job satisfaction and job stress reduction.

Nakashima and Canda stated that one of the factors contributing to the resilience of individuals is spirituality, and making meaningful narrative of life and death (personal meaning production); therefore, it can be concluded that spiritual intelligence can increase resilience [30]. Smith stated that having meaning and purpose in life is necessary to adapt to difficult and stressful conditions of life, and among them, the presence of supporting people is positive and significant predictor of choosing purpose and personal meaning by the individual. As a result, people with higher spiritual intelligence can easily adapt to their new situations, and this adaptation can reduce stress and enhance their performance [31].

Also Pan et al. stated that having meaning and purpose in life is one of the known protective factors affecting the resilience of individuals. In other words, those who are able to identify order, coherence and purpose in their lives, as well as those who have the ability to pursue and achieve their goals, show greater resilience in difficult life situations, and those who have higher spiritual intelligence, choose goals congruent with their abilities and with a particular discipline try different ways to achieve their goals, consequently, they can achieve their goals and desires without stress and with more power. Given that people with higher of spiritual intelligence have high level of creativity, honesty, happiness, interaction, organizational commitment, and conscience, they choose goals beyond material purposes. These features and trying to satisfy one and others result in compatibility, stress reduction, constructive, effective and successful interactions [32]. Also, people with high emotional intelligence have a high level of flexibility in every area of life and are happy and efficient which can result in health, prosperity, wealth, success, love and happiness. Studies also show that more than $50 \%$ of the success factor depends on emotional intelligence, and those with high emotional intelligence have broad social interactions and relationships, are more 
compatible with the environment and show high self-esteem and self-confidence. They are aware of their capabilities and are cognizant about their weaknesses and strengths. By this cognition, they can use their strong points and eliminate their weak points so as to achieve more success and experience less stress.

\section{Conclusion}

Based on the results of this research, it is suggested to the university authorities that by holding training workshops on spiritual intelligence and emotional intelligence for university staff try to increase their resilience and reduce their job stress. The Professors can promote collaboration among students in a variety of ways, such as collaborative approaches. These approaches increase students' social skills and their ability to understand others' emotions. It also increases their emotional intelligence. The professors will contribute to the development and growth of spiritual intelligence by discussing spiritual issues and transcendental dimensions, as well as they should encourage the students to think in areas such as wisdom, justice, spirituality, life, death, and life after death. Some of the research limitations include: lack of access to the level of intelligence and precise economic and cultural status and their impact on spiritual intelligence, emotional intelligence and resiliency of the students. We also did not have access to the level of emotional problems of the students and the level of the proper education that they have received. The results of the study is practical for clinical psychologists, counseling psychologists, university students, deputy of student affairs in universities, student deputy of Ministry of Science, science and technology of all students of universities.

\section{References}

[1] H. Naseri, Life skills, Deputy of Cultural and Prevention Affairs of the Welfare Organization of Iran, Tehran, 2007.

[2] S. Keshavarzi, F. Yousefi, Relationship between emotional intelligence, spiritual intelligence and resiliency, Journal of Psychology. 16(3) (2012) 299-318.

[3] D. Zohar, I. Marshall, Connecting with our spiritual intelligence, Bloomsbury Publishing, New York, 2000.

[4] D.D. Nasel, Spiritual orientation in relation to spiritual intelligence: A new consideration of traditional Christianity and New Age/individualistic spirituality, Doctoral Dissertation, University of South Australia, Australia, 2004.

[5] C. Haddadnia, N. Jokar, The relationship between spiritual intelligence and emotional intelligence with organizational citizenship behavior, A New Approach in Educational Management Scientific-Research Quarterly. 7(2) (2016) 157-179.

[6] R. Hassanzadeh, Motivation and excitement, Arasbaran Publication, Tehran, Iran, 2007.

[7] D. Goleman, Emotional intelligences: The Theory in Practice; Basic Book, New York, 1995.

[8] R. Bar-On, A measure of emotional and social intelligence in Chicago, Canadian Journal of Behavioral Science. 18 (1997) 123-137.

[9] R. Bar-On, Theory, development, assessment, and application at home, school and in the workplace; Jossey-Bass/Wiley, San Francisco, 2000.

[10] N. Eyvazi, Effects of emotional intelligence on family mental health, 2006. Available: http://www.aftab.ir.

[11] M. Kaschub, Defining emotional intelligence in music education, Arts Education Policy Review. 103(5) (2002) 9-15. 
[12] R.E. Boyatxzis, E.V. Oosten, Developing emotional intelligence organizations, in: R. Millar (Ed.), International Executive Development Programmes, 7th Edition, Kogan Page Publishers, London, 2002.

[13] M.A. Waller, Resilience in ecosystemic context: Evolution of the concept, Am. J. Orthopsychiatry. 1 (2001) 290-297.

[14] L.F. Page, R. Donohue, Positive psychological capital: A Preliminary exploration of the construct, Working Paper, Monash University, Department of Management, 2004.

[15] F. Dehghan, M. Piri Kamrani, J. Karami, The effectiveness of group spiritual therapy on resilience enhancement, Psychology and Religion Journal. 8(4) (2015) 81-92.

[16] B.W. Smith et al., The role of resilience and purpose in life in habituation to heat and cold pain, The Journal of Pain. 10(5) (2009) 493-500.

[17] M. Pinquart, Moderating effect of dispositional resilience on association between hassles And psychological distress, Journal of Applied Developmental Psychology. 30 (2009) 1-8.

[18] S.S. Luthar, D. Cicchetti, B. Becker, The construct of resilience: A critical evaluation and guidelines for future work, Child Development. 71 (2000) 543-556.

[19] N. Garmezy, A. Masten, The protective role of competence indicators in children at risk, in: E.M. Cummings, A.L. Green, K.H. Karraki (Eds.), Life span developmental psychology: Perspectives on stress and coping, Hillsdale, NJ: Lawrence Erlbaum Associates, 1991, pp. 151-174.

[20] M. Rutter, Resilience concepts and findings: Implications for family therapy, Journal of Family Therapy. 21(2) (1999) 119-144.

[21] A.S. Masten, M.G.J. Reed, Resilience in development, Handbook of Positive Psychology, Oxford University Press, New York, 2002.

[22] A.R. Hajian et al., The relationship between spiritual intelligence and emotional intelligence, Behavioral Sciences Research Journal. 10(6) (2012) 500-508.

[23] F. Baezzat, H. Sharifzadeh, Relationship between spiritual intelligence and emotional intelligence with job stress in university employees, Quarterly Journal of Career \& Organizational Counseling. 4(13) (2012) 55-68.

[24] D.B. King, Rethinking claims of spiritual intelligence: A definition, model, and measure. A dissertation presented in partial fulfillment of the requirements for the degree of Master of Science, Peterborough, Ontario, Canada, 2008.

[25] M.H. Chari, H.R. Zakeri, The effect of academic fields, religious and artistic sciences on spiritual intelligence: an approach to verification and determining the reliability of the spiritual intelligence scale, Quarterly of Educational Measurement. 1 (2010) 71-92.

[26] Gh. Dehshiri, The relationship between emotional intelligence with academic achievement of students, Counseling Researches and Recents. 5(18) (2006) 97-106.

[27] A. Fatemi et al., The relationship of the emotional intelligence and self-esteem with religious attitudes among the students, International Journal of Basic Sciences \& Applied Research. 3(3) (2014) 186-192.

[28] A.A. Samari, F. Tahmasbi, The study of emotional intelligence and academic achievement in university students, Journal of Fundamentals of Mental Health. 9(35) (2007) 121-128.

[29] F. Amini, The relationship between resiliency and burnout among nurses, Journal of Research Development in Nursing \& Midwifery. 11(2) (2013) 94-102. 
[30] M. Nakashima, E.R. Canda, Positive dying and resiliency in later life: A qualitative study, Journal of Aging Studies. 19 (2005) 109-125.

[31] B.W. Smith, The role of resilience and purpose in life in habituation to heat and pain, The Journal of Pain. 10(5) (2009) 493-500.

[32] J.Y. Pan et al., Meaning of life as a protective factor of positive affect in acculturation: A resilience framework and a cross cultural comparison, International Journal of Intercultural Relations. 32 (2008) 505-514. 